\title{
Editorial
}

\section{Update on the current situation with respect to COVID-19 in UK.}

\section{Aamir Khan}

Clinical and Information Governance, Public Health, England-UK.
Doi: 10.29052/JJEHSR.v9.11.2021.01-03

Corresponding Author Email:

aamir.khan@nhs.net

Received 07/01/2021

Accepted 23/02/2021

First Published 01/03/2021

(C) The Author(s). 2021 Open Access This article is distributed under the terms of the Creative Commons Attribution 4.0 International License (http://creativecommons.org/licenses/by/4.0/)

of black and Asian ethnicity individuals were associated with increased prevalence; healthcare and care home workers, and other key workers, were more likely to test positive than other workers.

- The report contains mobility data for the firsttime showing peoples' movement decreased at the end of December and increased at the start of January and helps explain the change in prevalence. spaces, and frequently washing your hands. There is no evidence to suggest whether this strain is more deadly than before. Initial findings from a study conducted by Imperial College London and Ipsos MORI show infections increased by $50 \%$ from early December, with 1 in 63 people infected. The interim findings from the eighth report of Realtime Assessment of Community Transmission (REACT), one of the country's largest studies into COVID-19 infections in England, suggest that infections in England have plateaued at the highest level with suggestions of a potential uptick. The report does not yet reflect the impact of national lockdown. The main findings from the eighth REACT study show:

- The national prevalence increased by $50 \%$, from $0.91 \%$ in early December to $1.58 \%$, or 158 per 10,000 infected.

- The national $\mathrm{R}$ was estimated at 1.04 .

- The prevalence increased nationally in all adult age groups and was highest in 18- to 24-yearolds at $2.51 \%$. Prevalence in the over $65 \mathrm{~s}$ more than doubled from $0.41 \%$ to $0.94 \%$.

- Large household size, living in a deprived neighbourhood, and areas with higher numbers

Data from Public Health England indicates that there are more people of all ages in hospitals in the U.K. with COVID-19 now than in the first wave of spring 2020, including the young and the old. Infections have been highest in teenagers, students, and people in their 20s and 30s in recent months, and the highest hospital admission rate for confirmed COVID-19 has been in the over-85s. There has also been a steep rise in the number of 65-74-year-olds and 45-64-year-olds admitted to intensive care units.

British officials have repeatedly said that without the emergence of the new variant, social distancing measures which have been in place across most of England since mid-October, including bans on most indoor gatherings, would have been enough to contain COVID-19.

But public health experts say government strategy on COVID-19 contributed to the surge in cases and the emergence of the new variant itself. Many have criticized the government's decision to considerably loosen restrictions over summer after the first lockdown in spring in order to try to revitalize the economy. Researchers at the 
University of Warwick found that a governmentbacked food voucher scheme, dubbed "Eat Out to Help Out," which encouraged people to dine at restaurants by subsidizing a portion of their meal, drove new infections up by $8 \%$ to $17 \%$ and accelerated the second wave in the fall. The scheme cost taxpayers almost $\$ 1.2$ billion.

The U.K.'s overall strategy for combating COVID-19 appears to have been driven by a different understanding of the virus compared to other countries with lower death tolls. The U.K.'s heavy toll comes down to an early decision to treat this like a flu-like event that would pass through the population with an uncontrollable spread that you would try to mitigate through building enough hospitals and medical care, rather than treating this like a SARS-like event, which is what East Asian countries have done, as well as the Pacific, Australia, New Zealand, as well as some countries in Europe, like Norway, Finland, Denmark, who are diverting from that flu model and trying to keep their numbers as low as possible.

There's no clear end in sight for England's lockdown. Although the government has tentatively set a date of mid-February to begin easing measures, the legislation on the new restrictions lasts until March 31. Transmission is so high that, according to government estimates, 1 in 50 people in England currently have COVID-19. The average is 1 in 30 or 1 in 20 in "hot spot" areas in the capital.

\section{Vaccinations}

The National Health Services (NHS) has been working to vaccinate the first two priority cohorts recommended by the Joint Committee on Vaccination and Immunisation (JCVI), which are care home residents and those aged 80 and over and frontline health and care staff. The NHS vaccinated a total of 4.06 million people between 8 December and 17 January, including more than half of those aged 80 and over and more than half of elderly care home residents.

This is more than double the number of vaccinations per person per day than any European country and is a significant step towards hitting the Prime Minister's target of offering vaccines to the top 4 priority groups by the middle of February. This group of around 15 million people accounts for $88 \%$ of COVID deaths, so vaccines will play a crucial role in saving lives and protecting the NHS.

Vaccinating the first two groups will remain the priority, but vaccination sites with enough supply and capacity for vaccinating further people are allowed to offer vaccinations to the next two cohorts - those aged 70 and over and clinically extremely vulnerable people. This will allow areas that have already vaccinated the first two groups to keep up the momentum and protect more people.

The vaccination programme continues to expand, with 10 large-scale vaccination centres coming on stream in England on the 21st of January 2021. The government is also urging people to play their part in the historic programme by:

- Helping out: help those aged 80 and over by supporting friends, family and loved ones with their appointments, as well as volunteering to help those in the community

- Joining up: sign up for clinical trials for COVID19 vaccines and treatments.

- Staying informed: keep up to date with accurate and trusted NHS advice and make sure to share facts with friends and family.

Where do we go from here?

There has been increasing pressure on the NHS with 15,000 people admitted to hospitals since Christmas Eve - over 20 hospitals' worth of new patients. While the vaccine programme continues to accelerate and expand to protect as many people as possible, with over 4 million people vaccinated, we do not know whether being vaccinated stops someone from passing the virus on to others. It will also be some time before the impact of the vaccination programme reduces pressures on hospitals. It is critical everyone continues to follow the rules, stays at home, reduces contact with others and maintains social distancing - remembering hands, face, and space. 
We have to remember that the findings from the REACT study show why we must not let down our guard over the weeks to come. As Matt Hancock, Health Secretary, has already stressed that:

- Infections across England are at very high levels, and this will have a knock-on effect on the already significant pressures faced by our NHS and hospitals.

- These findings show why we must not let down our guard over the weeks to come.

- It is paramount that everyone play their part in bringing down infections. This means staying at home and only going out where necessary, reducing contact with others and maintaining social distancing.

\section{Disclaimer}

The opinions expressed in this publication are those of the authors.

\section{References}

1. Ipsos MORI News \& Polls: News Latest Findings From COVID-19 Study Published (Updated December 15, 2020). Available at: https://www.ipsos.com/ipsos-mori/en-uk/latestfindings-covid-19-study-published

2. Official Statistics: REACT-1 study of coronavirus transmission: January 2021 interim results: Results of real-time assessment of community transmission of coronavirus (COVID-19) during January 2021. (Updated January 21, 2021). Available at: https://www.gov.uk/government/statistics/react-1study-of-coronavirus-transmission-january-2021interim-results

\section{D) Check for updates}

